\title{
Using a structured data management system to improve mine development efficiencies
}

\author{
E Savage Oyu Tolgoi LLC, Mongolia \\ T Moorcroft Oyu Tolgoi LLC, Mongolia
}

S Talu Rio Tinto, Australia

\begin{abstract}
A structured data management system has shown measureable improvements during two years of data capture, management, and analysis at the Oyu Tolgoi underground mine. This has directly led to enhanced contractor relationships between the mining contractor and the owners team, and underground development quality. CaveCad is an integrated data capture and storage system for capturing underground block caving related data. The CaveCad system has been used in conjunction with detailed data capture, through laser scanning of every excavated development round. This is undertaken immediately after mucking and then again directly following the installation of ground support. This results in detailed $3 D$ as-builts which are used for measuring a number of quality control metrics including resin encapsulated rebar and cable bolt spacing, mesh overlap, shotcrete thickness, and excavation compliance to design. The data collected from this process is used for tracking compliance to both excavation and ground support design, and, where required, rectification of issues by the contractors when installations are non-compliant.

In the past, serious safety incidents have occurred in the mining industry due to a lack of detailed understanding of the true as-built of the mine, along with a lack of understanding of the history, location, and quality of installed ground support material. The strategy of keeping a specific team for data management and analysis was directly related to the decision to laser scan all blasted headings underground, to mitigate these potential risks and knowledge gaps, and to ensure high-quality usable data is available throughout the mine life. A detailed $3 D$ as-built plan is available for both the excavation and installed ground support, which can be referenced at all times by all mining personnel.

The results of this detailed data capture show improvements over time in both quality and efficiency of the mining process. This includes a reduction of shotcrete overspray and over-bolting issues and a marked decrease in excavation overbreak from the designed tunnel profile, resulting in an increase in compliance to excavation design. This has enabled Oyu Tolgoi to improve accuracy of mining, quality of the ground support installation, reduction in wastage (e.g. shotcrete), and improved, better informed discussions with contractors regarding key performance indicators that incentivise them. High-quality and qualitative data management has also allowed for fast and reliable data sharing between stakeholders, reducing any potential knowledge silos and enabling improvements to be made to the mining cycle based on actual lessons learned.
\end{abstract}

Keywords: data management, contractor management, laser scanning, geotechnical data, quality control, CaveCad, reporting

\section{Introduction}

The Oyu Tolgoi (OT) underground project, located in the South Gobi Desert of Mongolia, restarted in July 2016 (Phase 2) following a period of care and maintenance (Phase 1). In Phase 1, 18,930.9 m of development was completed. Since restarting development in May 2016, until July 2018, 12,795.7 m has been excavated, bringing the total excavation of the underground project to $31.7 \mathrm{~km}$ development, including vertical and lateral development. Due to the long expected lifespan of mining the orebody and 
the complexity of the excavations, a focus was placed on accurate data capture, validation, and storage. Production of Hugo North Lift 1 as an underground cave operation is expected to last through to 2039, with a planned second lift to follow. To support mining, over $137,000 \mathrm{~m}^{3}$ of mass excavations will be excavated comprising of approximately $200 \mathrm{~km}$ of lateral development, five shafts, $5 \mathrm{~km}$ twin declines and $7 \mathrm{~km}$ of vertical raiseboring (Oyu Tolgoi LLC 2016). It is important that an accurate and traceable record of the data associated with underground development is available throughout the mine's long lifespan for all excavation areas and types. This is vital to ensuring ground control related incidents do not occur due to lack of recording of the quality, quantity and type of ground support previously installed.

The CaveCad system was developed by Rio Tinto for the purpose of ensuring secure and robust management of geotechnical data during both the development and production phase of an underground mine. It is an integrated geotechnical data management system, capturing a range of production data, geotechnical monitoring data, geotechnical mapping, and ground support installation quality data (Savage et al. 2016, p. 769). The CaveCad system has been used in various stages of mining before implementation at OT, i.e. Rio Tinto's Argyle Diamond Mine for data capture and storage in a producing block cave mine, and the Kennecott Utah Copper mine (RTKC) for data capture and storage in an underground development. Data is stored in one common database, creating a single coherent system that all users can access. CaveCad includes automatic data importing, remote (offline) data collection through tablet applications, and scheduled or ad hoc reporting of processed and analysed data.

The scale, both temporally and spatially, of development at OT means that relying on traditional methods of data capture (whereby engineers and technicians take measurements manually and record them on paper and in photographs) would require a very large workforce and impact the development cycle. The implementation of the system accounts for $\sim 14 \%$ of the geoscience department staffing at OT. Trials at RTKC demonstrated that accurate 3D laser scanning of excavations pre and post ground support is a reliable way of capturing large quantities of data in 3D with minimal impact to the development cycle. A significant amount of effort has been invested to ensure that data is captured with sufficient granularity to allow for the assessing of detailed observations and interpretations.

\section{Data flow process}

\subsection{Data management structure}

CaveCad is the central repository for captured geotechnical data. However, there are a number of other components included as part of the overall data management system, as outlined in Figure 1:

1. Data is collected through laser scanning of headings after blasting.

2. Scan data is geo-referenced and processed to provide excavation compliance to design, and ground support installation quality control (QC) data that is then transferred into CaveCad.

3. Data is also captured through face mapping onto tablet devices through an app linked into CaveCad. A different app facilitates the collection of ground support QC information observed while the geotechnical engineers inspect each heading.

4. The tablet devices are synced, and this data is stored in CaveCad.

5. Non-conformance reports are issued for areas that are non-conformant to design, and these are then fixed and re-inspected until they are compliant.

6. Data are then reported out of CaveCad at various regularities, including reports for each heading, feeding into weekly, monthly and annual reports issued to the workforce and management. 


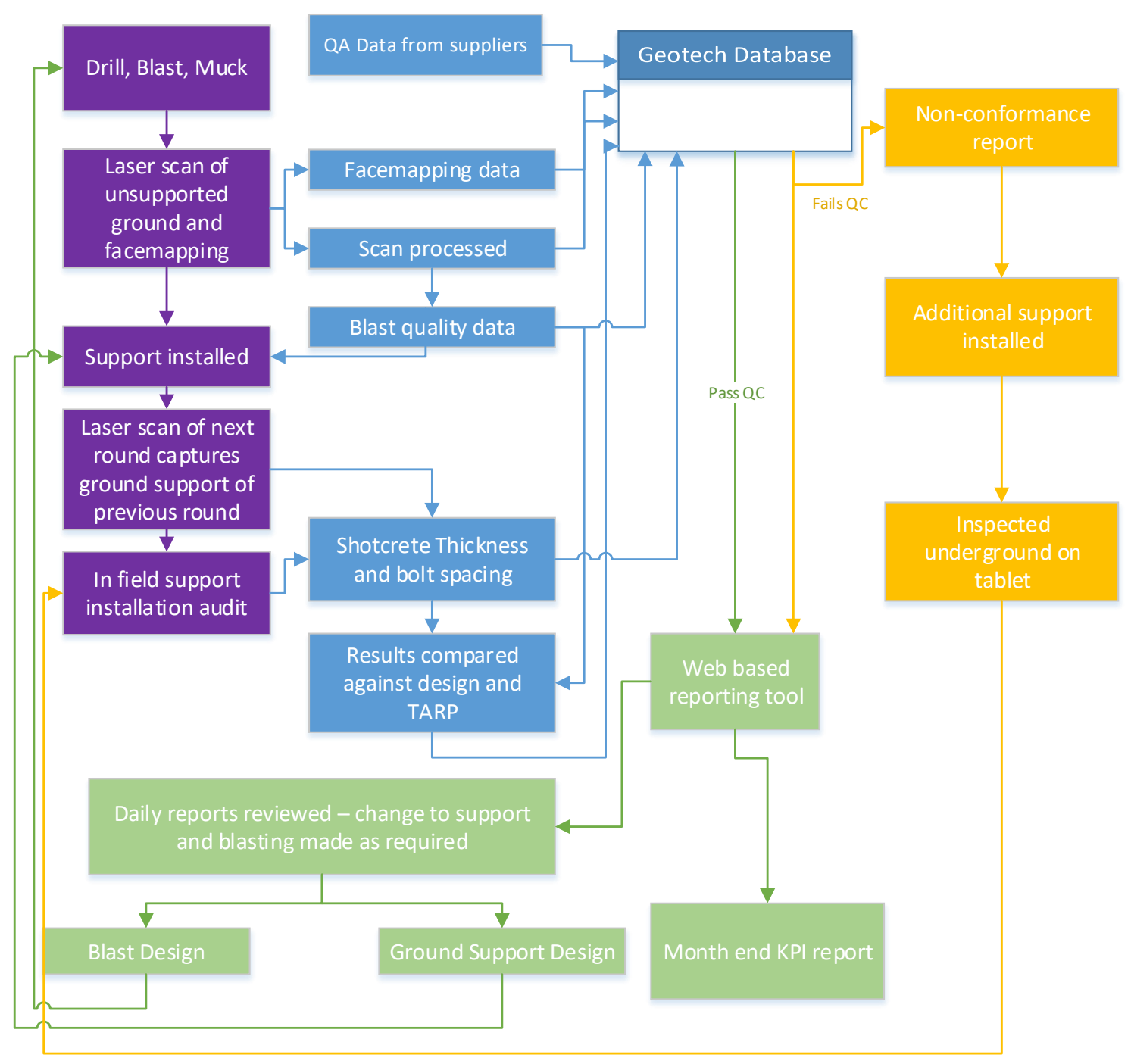

Figure 1 The structure of data management at OT from mining processes (purple), to data collection (blue), to non-conformance reporting where necessary (yellow), and reporting and analysis of validated data (green)

\subsection{Quality assurance of ground support materials}

Due to the remote location of OT, procurement of incorrect or non-compliant ground support materials have the potential to cause significant delays to the delivery of materials and can cause delays to the development cycle whilst compliant materials are re-ordered. Worse, if non-compliant ground support is installed, a heightened safety risk is created. This causes substantial delays to development due to the need to rehabilitate areas and results in significant additional cost due to the replacement of incorrect support materials. Prior to the restart of the mine in 2016, it was acknowledged that a robust quality assurance program was required in Phase 2 to track the specification compliance of material supplied and installed underground.

The requirements of quality assurance testing were included in contracts with suppliers and a clear understanding was reached between the underground project geotechnical department, OT procurement, and external suppliers, concerning the importance of quality material being supplied underground.

All ground support materials approved to be used in the mine have a series of specifications that are stored in CaveCad and provided to suppliers for testing standards. Testing results are sent to the underground project geotechnical department before the batch of material arrives onsite. The data is tracked against the approved standards in CaveCad to ensure the batch is compliant to material specifications. 


\subsection{Laser scanning}

\subsubsection{Excavation actuals}

Laser scanning, both before and after ground support installation, was included in the data capture process of each development round from the beginning of Phase 2 of the OT underground project. At OT, a compact, high-speed phase-based laser scanner with an integrated camera is used (Zoller + Froehlich GmbH 2018). The scanner is manually transported to active headings once mucking is complete, and a scan is taken of the unsupported face. This process takes approximately 20 minutes, including setting up the instrument, setting spatial control (carried forward down a drive and periodically surveyed to minimise spatial drift), and undertaking the scan itself. Depending on the settings of the scan and whether or not colour photos are also taken, the scan time varies; approximately 15 minutes to capture a full colour point cloud and reduced to seven minutes to capture a laser reflectivity point cloud. Photos are not necessary, as the scan itself is of a high quality in dark underground environments through using the reflective index of surfaces to colour the points (Figure 2). It has, however, become standard practice to set up high-powered lights to take additional colour images using the scanner, as the additional time is minimal, and the colourised scans can then be used for geological analyses.

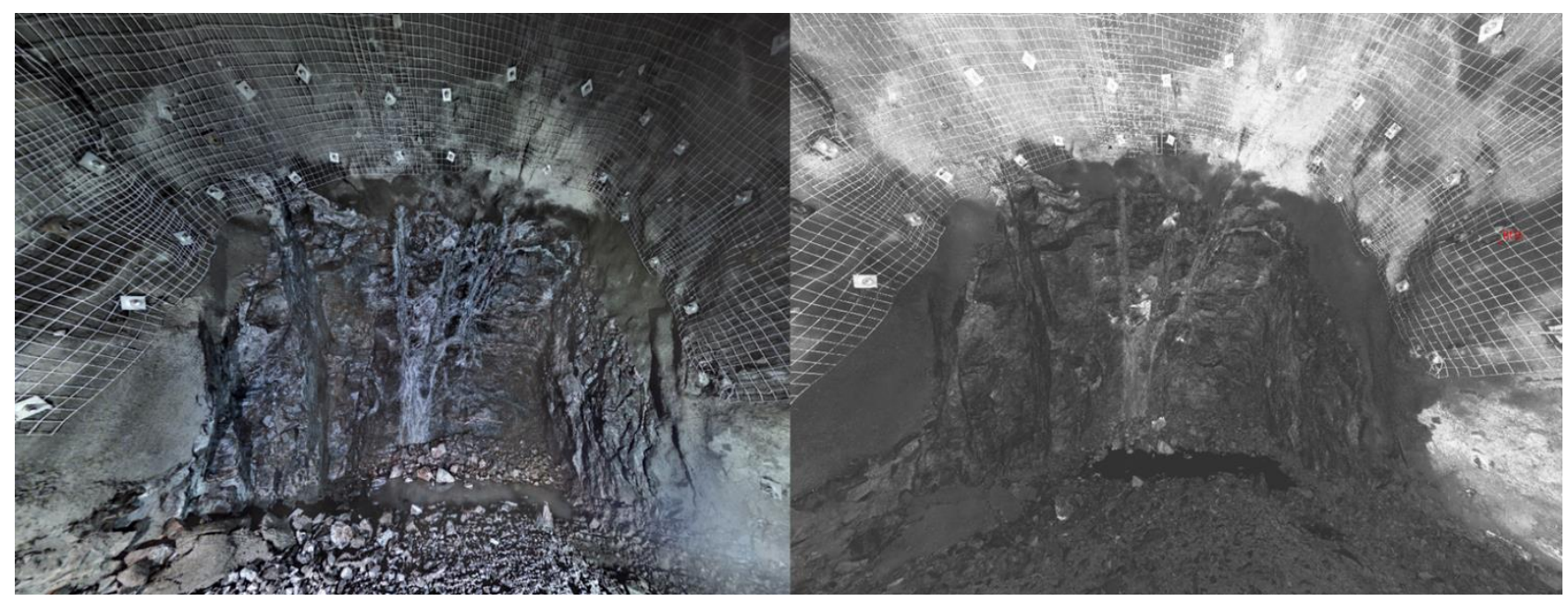

(a)

(b)

Figure 2 Examples of colour scans using; (a) The inbuilt digital camera; and, (b) The reflective index image produced by a standard scan. Images are unclear when looking away from the light source in colour photos, but the reflective index scan can see accurately in all directions

Excavation as-built data captured and calculated from these scans includes:

- Development round length.

- Overbreak (as-built profile outside of designed profile) and underbreak (as-built profile inside designed profile) volume against a design solid.

- Overbreak and underbreak percentage.

- Blasted volume.

- Misholes or bootlegs.

- Underbreak (yes/no).

- Half barrels (yes/no). 
Each scan contains six target points, which are used as survey control to geo-reference the scan to the mine grid. By installing additional points every round, it has been possible to carry control down drifts. This allows scans to be taken every round without putting significant load on survey resources.

\subsubsection{Ground support installation}

The laser scans provide an accurate record of the ground support installed in the previous development round. Where possible, scans are used to undertake QC of ground support installation, which removes people from potentially dangerous situations underground, and reduces cycle time delay due to data capture.

Bolt and ring spacing data are captured for every bolt in every heading, such that a record is also kept of the number of bolts installed (Figure 3). An accurate and representative average of the spacing per heading is reported against the design, and any missing bolt can quickly be identified and requested to be installed. The height of the lowest bolts is also measured and captured (where installation of the lowest row of bolts is trailed behind the face), to ensure ground support, as a whole, is still compliant and the heading is accurately supported.

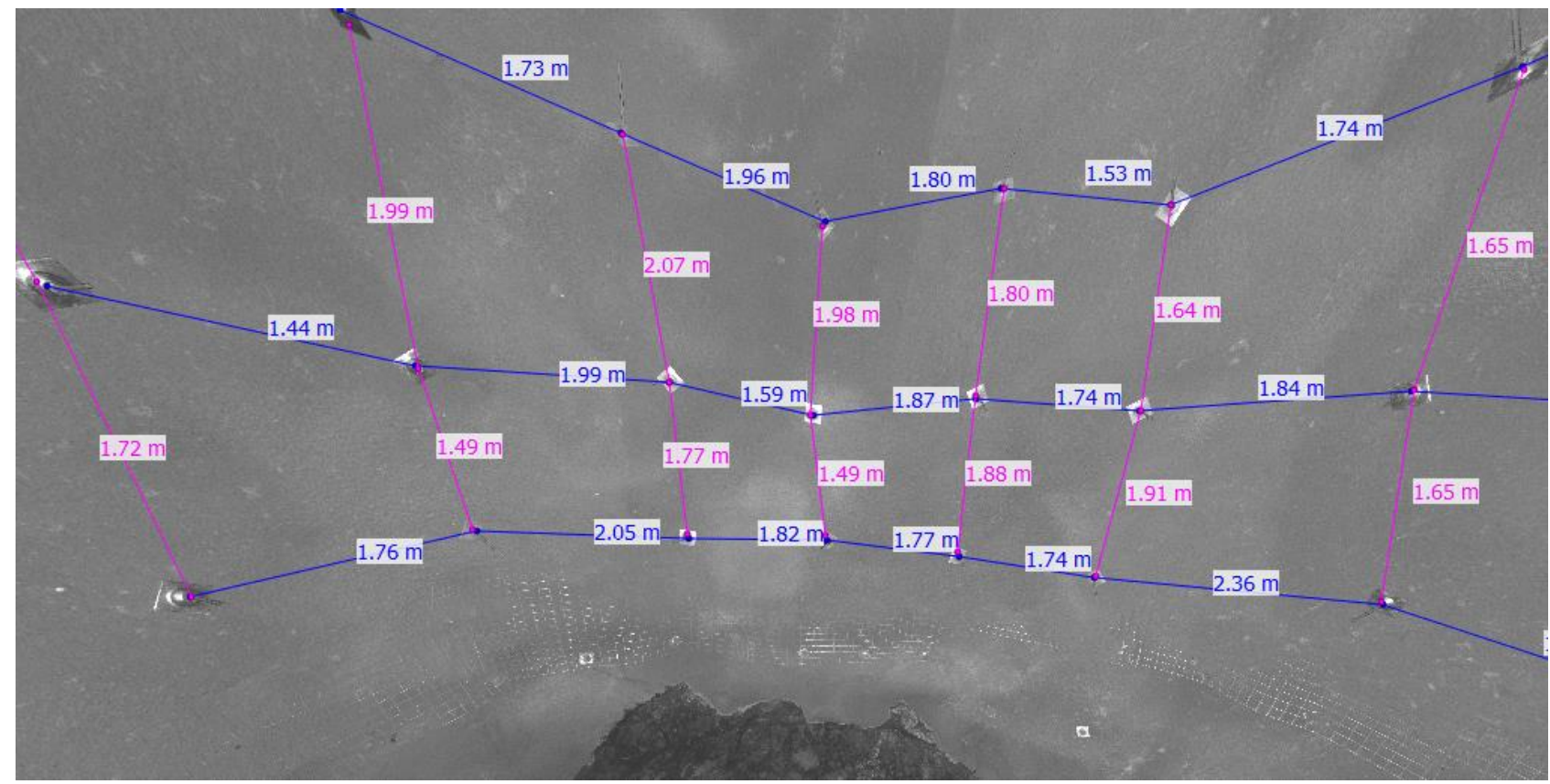

Figure 3 Bolt spacing compliance can be measured quickly and accurately from a laser scan, on surface. This reduces the risk of a person standing for extended periods of time at the face measuring spacing, delaying development and increasing their personal exposure risk. Support for this round was designed as $1.8 \times 1.8 \mathrm{~m}$ bolt spacing (blue - ring spacing, purple - bolt spacing)

Mesh overlap widths are also captured from the laser scan to ensure the integrity of the mesh is maintained in the event of convergence.

By taking a scan of each development round, the unsupported face in 3D can be compared to the supported development round in the next face scan. This allows accurate modelling of the shotcrete thickness over the whole area of each development round, producing an accurate spatial understanding of the shotcrete thickness (Figures 4 and 5).

Occasionally, due to rock fallout or scaling between the first scan and the second scan, measurements may be difficult in some areas where the walls have advanced beyond the thickness of the shotcrete. This can cause potential inaccuracies in the reported shotcrete thickness. Where shotcrete thickness is below design tolerances, this is first ground-truthed by the geotechnical engineers, and if necessary, rectified with mesh or a second pass spray of shotcrete. 


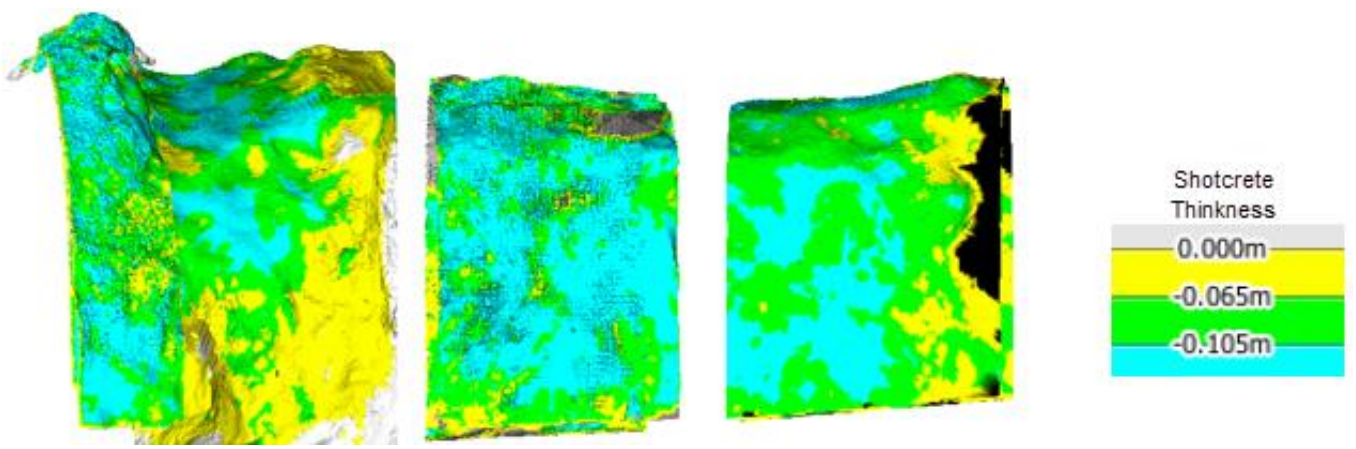

Figure 4 Shotcrete thickness can be seen in 3D. Yellow is below designed thickness, green is within design limits, and blue is above designed thickness

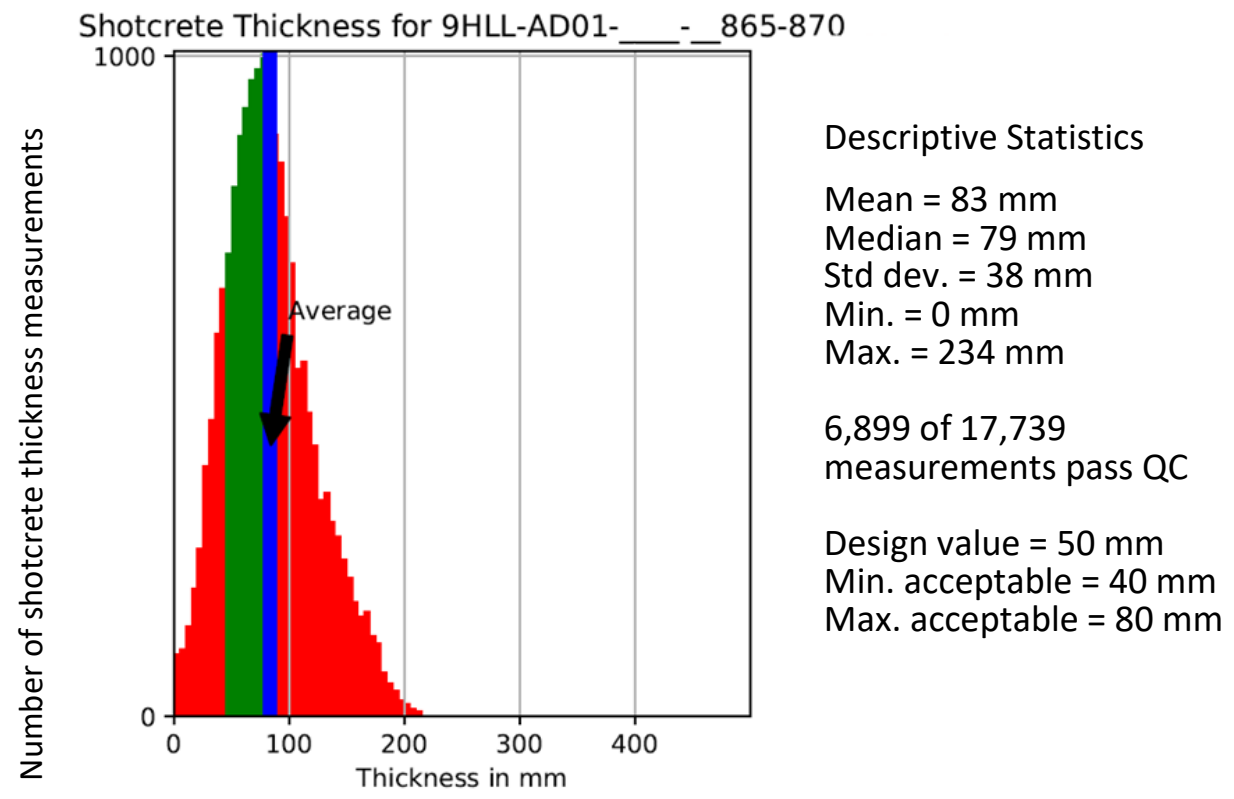

Figure 5 Shotcrete thickness for the whole development round is processed quickly and can be presented visually in 3D - 17,739 measurements per development round, for example, compared to traditional drilling methods where 6-10 measurements may be taken

\subsubsection{Structural orientation from laser scanning}

Laser scan data is also used to highlight major structures, to compare to and possibly validate mapped face data and to do a more detailed analysis of ground structural characteristics. Since typically the face maps are manually captured underground by standing $5 \mathrm{~m}$ back from the face under supported ground using a compass, the data can, in some cases, be less accurate. The scans can validate the structural detail of the area and add this data to mapped lithology and other general rock conditions that are better identified underground at the face.

\subsubsection{Handover of areas between teams}

Where handovers of areas between teams are required, data is packaged and verified by the survey team before being delivered to the necessary stakeholders. This may include handover of mass excavation areas from the development team to the construction team. Accurate scanning and 3D as-builts allow the construction team to pre-design the steelwork, for example, to a more accurate degree than prior, meaning less waste upon arrival on site by removing identified underbroken areas. Concrete pours are also a lot more accurate as a better understanding of cement amounts required can be produced from the volumetric area of the pour's location. 


\subsection{Other methods of data capture}

In addition to the data captured from scans, underground inspections of ground support are carried out. These are recorded on tablets and a specialised application syncs the data once the tablets are online (on surface). This improves the quality of the data captured through using specific lookup codes, which can be searched and grouped easily due to consistent input. It should be noted that the use of codes does tend to categorise the data, and thus reduce the use of subjective descriptions which can provide very valuable data. Interpretive descriptions can be entered as a free text comment, which is reported as part of the categorised data. The use of tablets over paper records also reduces risk of data loss through accidental loss or destruction of the paper record.

Data captured on the tablet includes multiple tests/observations for each ground support type as per the OT ground control management plan and records results from other QC tests that cannot be observed from the laser scan, such as pull testing and resin encapsulation length.

Ground support installation quality audits are undertaken periodically, and this data is also captured in CaveCad. These observations aim to ensure all operators are installing support to manufacturer specifications, and to document and capture data that cannot be observed after installation is completed. Data captured includes resin spinning time, drillhole diameter, hole length, length of bolt installed, etc.

Face maps are conducted on each development round to enable rock mass characterisation of headings. These are recorded directly onto a tablet application, which facilitates mapping on a photo of the face. Parameters for rock type, joint spacing, joint infill, alteration types, etc., are all available as lookup fields. Each face map has multiple calculated results for various rock mass classification schemes available (including RMR ${ }_{89}, I R M R, G S I$ and $Q^{\prime}$ ). These results can then also be synced to CaveCad once the tablet has a network connection, enabling the mapping results (both data and the face visualisation) to be captured directly into the database. Face map data can then be compared directly against other geotechnical data to provide useful analysis and data input into, for example, geotechnical numerical analyses.

\subsection{Management of data and tracking of development process}

CaveCad captures data during all phases of the development cycle; from the issuing of an area development plan to final QC reconciliation of the ground support installation.

Mine drives are stored with 3D coordinates in CaveCad and all data is stored against drive and chainage, so all data can be referenced in 3D space and mapped if necessary. Ground support designs are entered and stored in CaveCad. The designs are assigned to a drive and chainage once the approved development plan is issued. The designs also include quality assurance (QA) and quality control specifications. So any data coming from suppliers (QA) or collected from scans or underground (QC) can be compared to these specifications and a pass or fail can be produced automatically for each area.

Installation details are captured including results of audits and the status of installation in various headings and non-compliances. This allows an easy mechanism for tracking the multiple stages of installation required in some designs. Geotechnical staff can easily track which headings have had ground supported, been $Q C$ checked, finalised, etc.

Where second pass ground support is required (including installation of cable bolts and second pass shotcrete) after the first pass of ground support has been completed, a second laser scan is taken. This ensures the final thickness of the shotcrete is compliant with the specification, cable bolt spacing and location are correct, and other second pass support such as Osro straps or dynamic units are installed as per design. Second pass compliance is tracked by mapping the QC results from the database. Intersections are clearly assigned which status the area is in (installed, quality controlled, signed off, etc.). 
QC data, which can only be finalised at a later date, such as 28-day strength tests on shotcrete, can be added with the locations where they were sampled. This enables the systematic data capture and storage structure allowing for a full-scale record of the design, installation, and QC of all areas on both temporal and spatial scales.

\section{Benefits from data management process}

\subsection{Faster processing and analysis}

As soon as a heading has been blasted and the laser scan data processed, the measured excavation attributes are added into CaveCad. Face maps and ground support QC data is also synced into the database within a few hours of capture. This will be reduced to near real-time with the roll out of the underground WiFi network. The geospatial structure of the database allows for design, excavation actuals, ground support quality, and ground condition data to all be easily searchable, and for disparate data to be quickly compared and analysed.

Calculations and manipulations of the data can be undertaken quickly and easily, as the data is already in a comparable format and validated. Sorting by date of entry, date of excavation, location, ground support type, geology type, etc., is all easily done, making data analysis a simple process. Because data management is well structured, data captured during the development process can be interrogated and reported on in a timely fashion, making it useful as it is fed back into the mining cycle. It can also lead to process changes and continuous improvements.

\subsection{Reporting}

\subsubsection{Monthly reports}

Monthly reports are produced for every development area within the OT underground project. These are used to track contractor compliance to key performance indicators (KPIs) per month, including compliance to excavation design and compliance to ground support design. Monthly reports include average overbreak percentage, number of rounds achieved, and compliance to design of shotcrete thickness, bolt spacing, and pull testing.

\subsubsection{Weekly reports}

Weekly reports are produced for reviews in some areas, such as shaft sinking, where daily reviews would be too frequent. Reports are easily created through a database linked to a web-based reporting platform, and contain information such as the overbreak and underbreak metrics, the concrete curb pour volumes for shaft sinking (automatic calculation based off the volume difference between as-built and curb diameter design), pull testing results, and other QC values. Because data is validated on entry and stored in a robust system, these reports are easily produced. These reports are also published to internal web pages so they are available throughout the week to anyone who has access to the Rio Tinto network, across the globe.

\subsubsection{Development round reports}

For every heading, a development report is created in both Mongolian and English, outlining the compliance to design and the performance of the blast (measured through development round length, blasted volume, etc.). A 3D visual of the development round is also shown, which has corresponding drill log files included, allowing drill and blast teams to reconcile and identify any improvement to be made for the next development round. Figure 6 shows an example where high overbreak occurred and the changes made to control it. 
A second report for each development round is released once the next development round has been taken and the QC data of the previous development round is available. This shows histograms for the results of bolt and ring spacing, distance of lowest bolts from the floor, and shotcrete thickness, including whether the area has passed or failed. Where QC data has failed and is deemed non-compliant to design, a non-compliance report is immediately issued, detailing the additional support requiring installation to meet the design specifications. These are completed with the next round of support installation, meaning a clear compliance history is tracked and areas are fully supported within a timely manner after development.

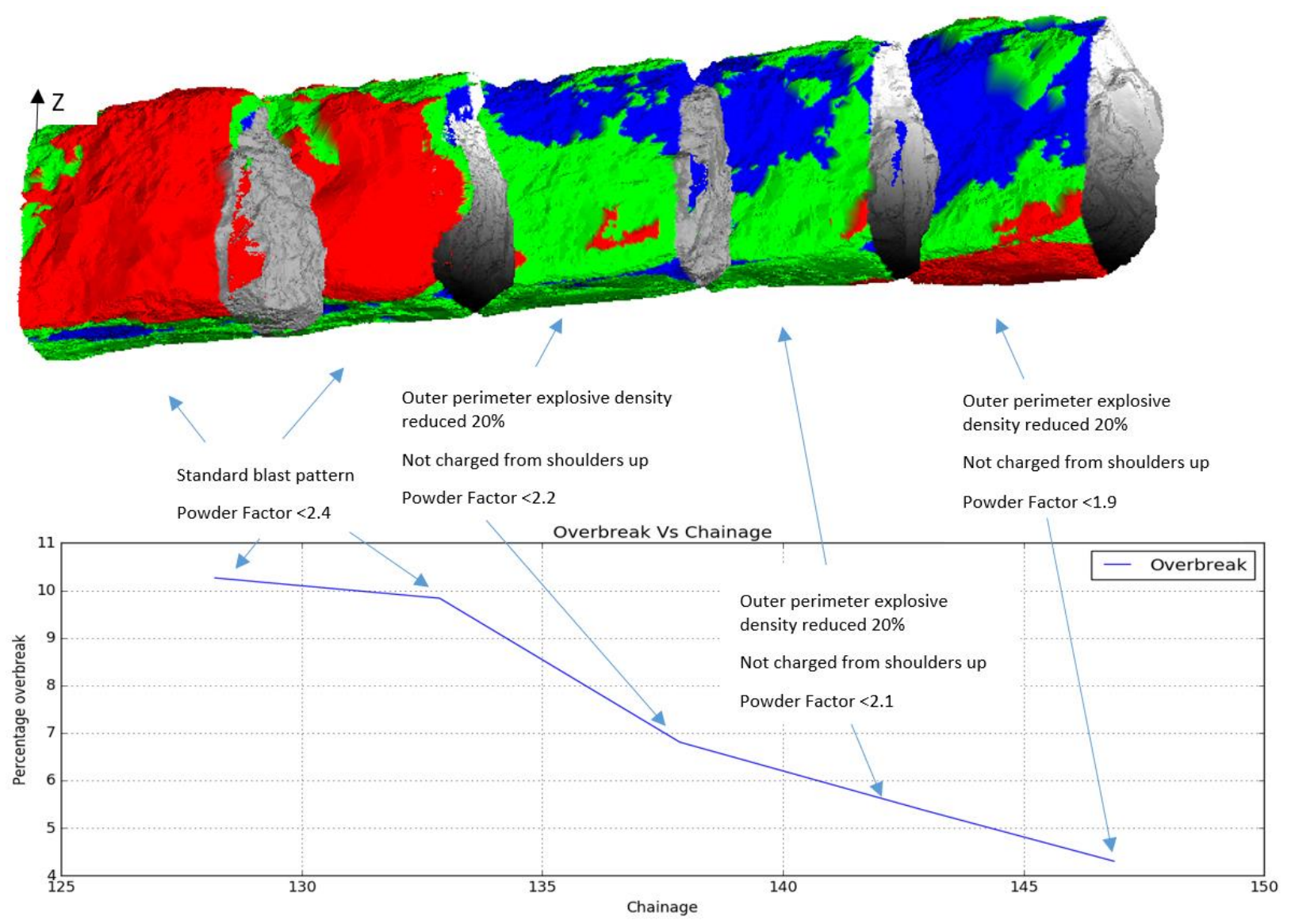

Figure 6 Upper: 3D scans of five blasts coloured by blast design compliancy. Red - overbreak, blue - underbreak, and green is within design tolerances. Lower: The overbreak percentage per round and the changes to the blasting which was carried out

\subsubsection{Other reports/analyses}

Storing data in one validated database also allows in-depth analysis to be undertaken, comparing disparate data sources and finding trends which may have otherwise not been possible due to time or data availability constraints. Analyses can be undertaken quickly and easily on how various causes and external factors affect the quality of excavation. For example:

- $Q$ and Mining Rock Mass Rating (MRMR) versus overbreak.

- Analysis to determine the relationship between ground conditions and excavation results.

- Overbreak in the shaft versus shaft quadrant.

- Analysis to determine whether overbreak is more or less prominent in certain areas of the shaft barrel, in order to optimise blasting to minimise underbreak.

- Overbreak versus drive orientation

- Analysis to determine the effects of stress directions and drive orientation on overbreak. 
- Various controlling factors for overbreak frequency analysis.

- Following a morning meeting, a reason is assigned to each development round where overbreak and underbreak are outside of the design tolerances. Grouping these can help the technical teams identify areas for improvement in terms of blasting quality, whether that be blast designs, ground conditions, issues with drill rig navigation calibration, etc.

\section{Outcomes and benefits to Oyu Tolgoi}

\subsection{Use of the system to improve development efficiency}

Development results and ground support QC reports are published, on average, within 12 hours of the round being developed or subsequently supported. Reports from the last 24 hours are then reviewed with all stakeholders each morning and actions are discussed to improve where necessary. This rapid reporting and feedback process is essentially collecting and processing, contributing a vast array of data to actual improvements and feedback in the development cycle. It is not just data collection for interest's sake; material gains are realised too.

Daily reviewing of development quality reports brings visibility to problems such as calibration errors in machinery and/or issues where survey lasers are effected by blasting or ground movement. With mine surveying taking place in non-critical headings approximately every third face, these errors could otherwise propagate further and result in significant re-work at a later stage. This has also allowed poor operating practice to be identified and corrected. Overbreak, due to adverse geology, can be recognised quickly and the feedback of blast design reconciliation in this ground can be reviewed and improved before the next development round is taken. This minimises the damage to the ground in poor rock mass conditions and improves the efficiency of the development cycle as less overbreak results in less unnecessary mucking and less additional support. Conversely, where areas are underbroken, the drill pattern and blasting design can be revised such that the next round can be compliant, minimising the time required if stripping of underbroken areas is needed.

Analysis of the data collected from the use of a structured data management system has shown a number of material improvements at OT. The average overbreak percentage per month has steadily decreased since the project restarted in 2016 (Figure 7). Display screens have been installed in the muster room to ensure operators have access to the data produced from scanning, so they can review and take ownership of the results of their work.

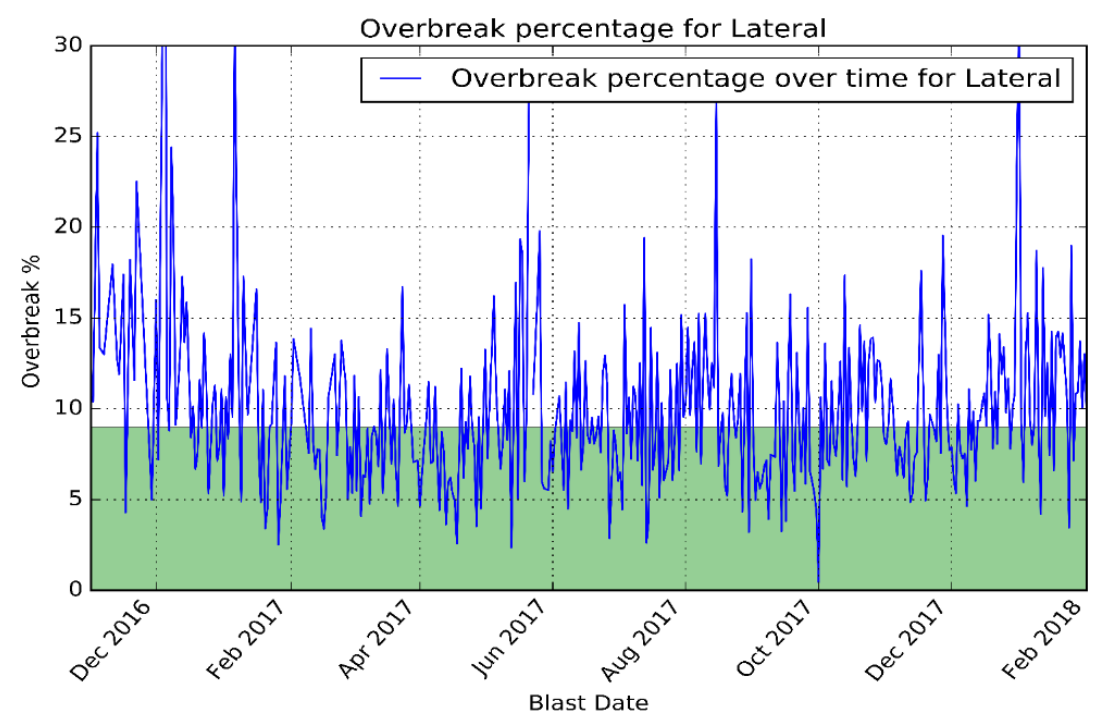

Figure 7 Plot of overbreak against time showing average overbreak reducing from $15 \%$ at the start of the project down to $9 \%$ in December 2017 before rebounding to $12 \%$ in February 2018 . This represents $\sim 6.5 \mathrm{~km}$ of development 
The increased overbreak in February is attributed to a change in blasting product. This change increased fragmentation and reduced the load on the underground crusher.

Shotcrete overspray has reduced since the project restarted, through detection due to detailed laser scanning. Through a combined effort from multiple departments, when overspray was detected, a more accurate volumetric guideline was provided to operators based on profile dimensions. As a result, overspray has decreased significantly, leading to substantial savings in cement consumption. Savings in the order of USD 500,000 have been realised due to reduced overspray volume (Figure 8).

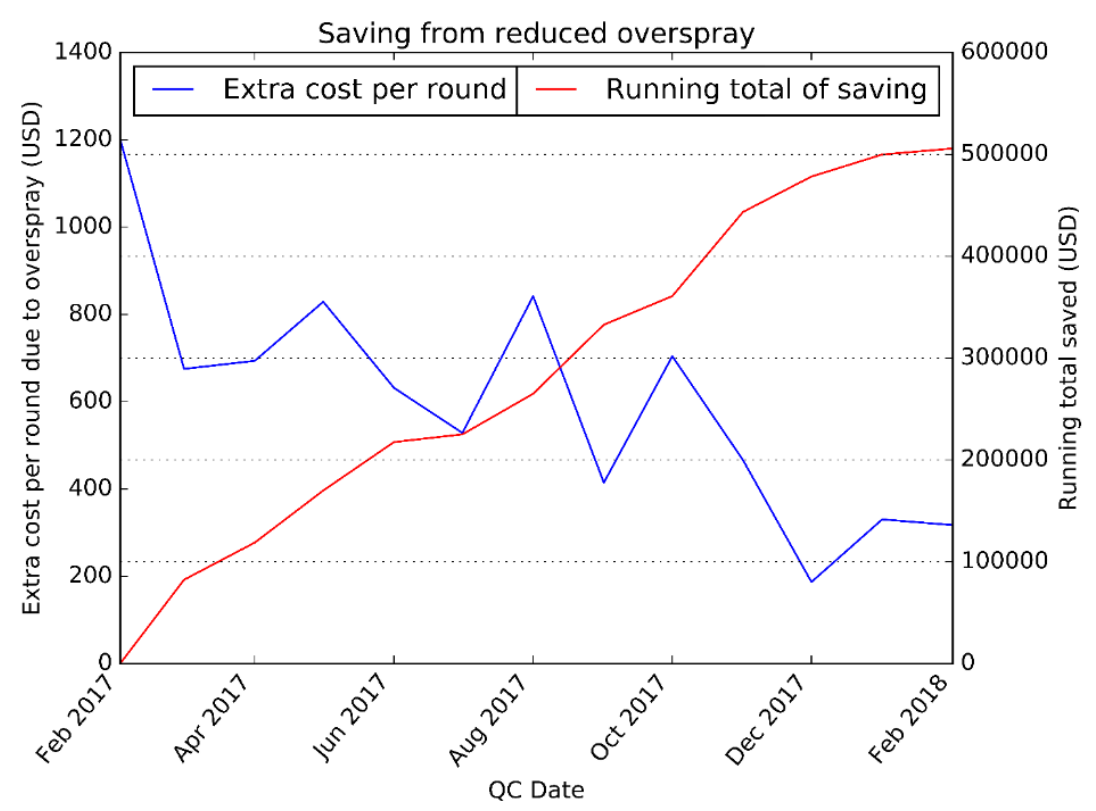

Figure 8 Plot showing reducing overspray cost and cumulative savings as a result of improved shotcreting feedback and control

A 15-minute scan to collect data, which can provide various measurements, also reduces the amount of time the geologists and geotechnical engineers need to spend at the face. This has allowed for improved efficiency in the development cycle.

\subsection{Use of the system to improve safety}

Having an accurate 3D as-built of the entire mine development is very useful to manage development breakthroughs. Mine personnel have an accurate understanding of each drives' position in space and relative position of the active drive breakthrough and other drives, in more detail than a single face stop line on a 2D survey plan. Cable bolt designs can be created based on the actual position of the drive and any potential interactions can be considered to minimise the safety risk of drilling into other headings.

By undertaking ground support QC off laser scans, the time spent underground near unsupported faces is minimised. The approximately 15 minutes it takes to do the scan can be spent mapping the face and collecting the scan in one go, and then for the previous rounds' QC including bolt spacing and shotcrete thickness. This allows for more time for additional underground inspections such as damage mapping and pull testing. 


\subsection{Efficiency leading to more accurate data processing}

Improvements in the analysis and processing of the data have provided increased accuracy. From commencement of the data management system, a representative sample of QC measurements from laser scans was manually selected, introducing a high level of human bias (e.g. two rings of spacing were measured instead of all in the round). Due to increased efficiency of the data processing cycle, it became possible to remove this bias and measure all data. Currently, all bolt tails are selected in every heading (for spacing measurements), which not only allows for an accurate spacing average, but for minimal overall extra work it records the number of installed bolts per round which are then stored in the database with their exact XYZ coordinates in space. It was found that by removing the human bias, and an apparent tendency to choose the worst case scenario (Figure 9), the actual average of bolt spacing was better than previously measured, and the spread in the data reduced. A more representative and consistent measure of the bolt spacing is now captured.

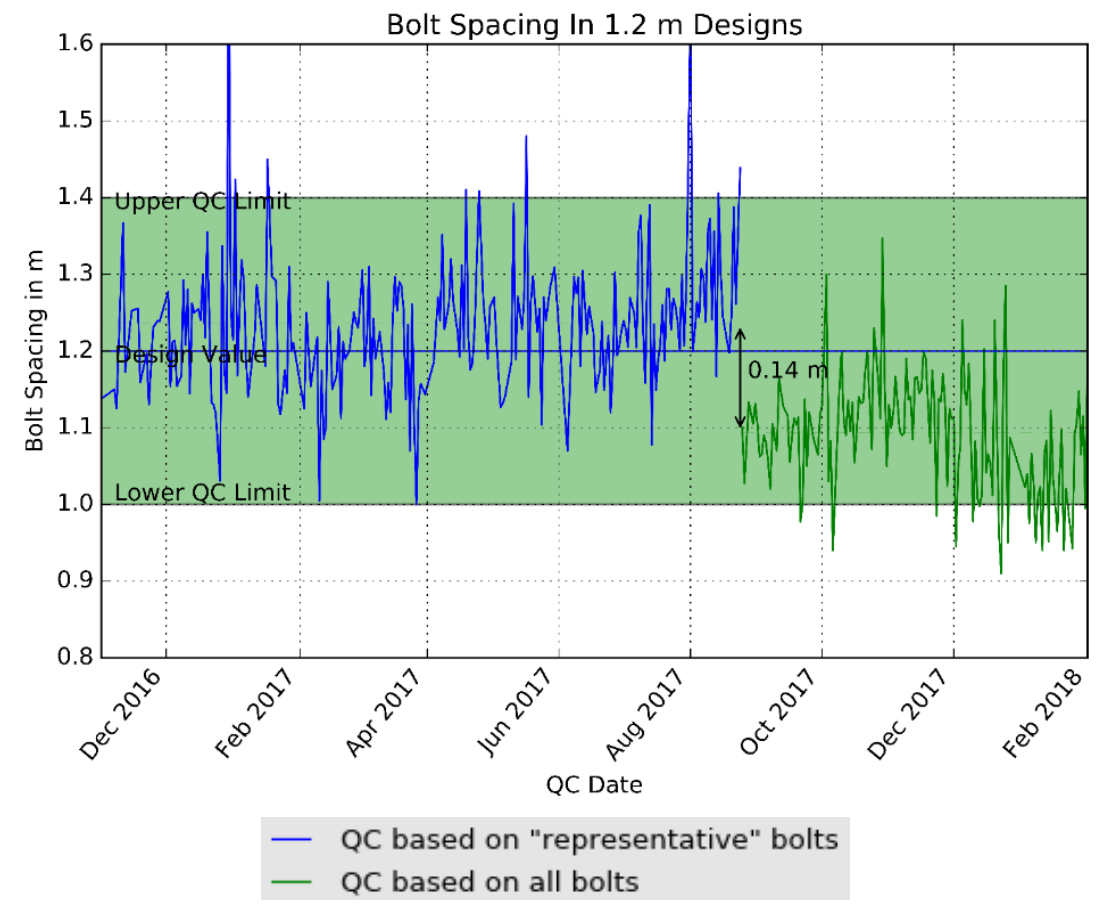

Figure 9 Bolting spacing for $1.2 \mathrm{~m}$ design patterns. A step of $0.14 \mathrm{~m}$ occurs in the data when changing from human selected bolt measurements (in blue) to a system which includes measuring all bolts spacing (green). This represents $\sim 6.5 \mathrm{~km}$ of development

Following the project restart, users manually cut six cross-sections through the scans of each round to measure shotcrete thickness, and took six measurements around the profile in each section for a total of 36 measurements over a 5-6 m round. While a good representation, it was not accurately capturing detail and thin areas observed underground which were often not represented in thickness results from the scans. Changing the process to a comparison of the pre-support scan to the post-support scan by the software led to the collection of 1,000 times more shotcrete thickness points per round. As was seen earlier (Figure 5), a total of 17,739 shotcrete thickness measurements was collected for this round; 6,899 of which are within the design specifications for shotcrete thickness. This average is therefore much more reliable than the one based off 36 measurements, and has removed the human bias. It is interesting to note that no major change occurs in average shotcrete thickness, unlike bolt spacing (Figures 9 and 10). 


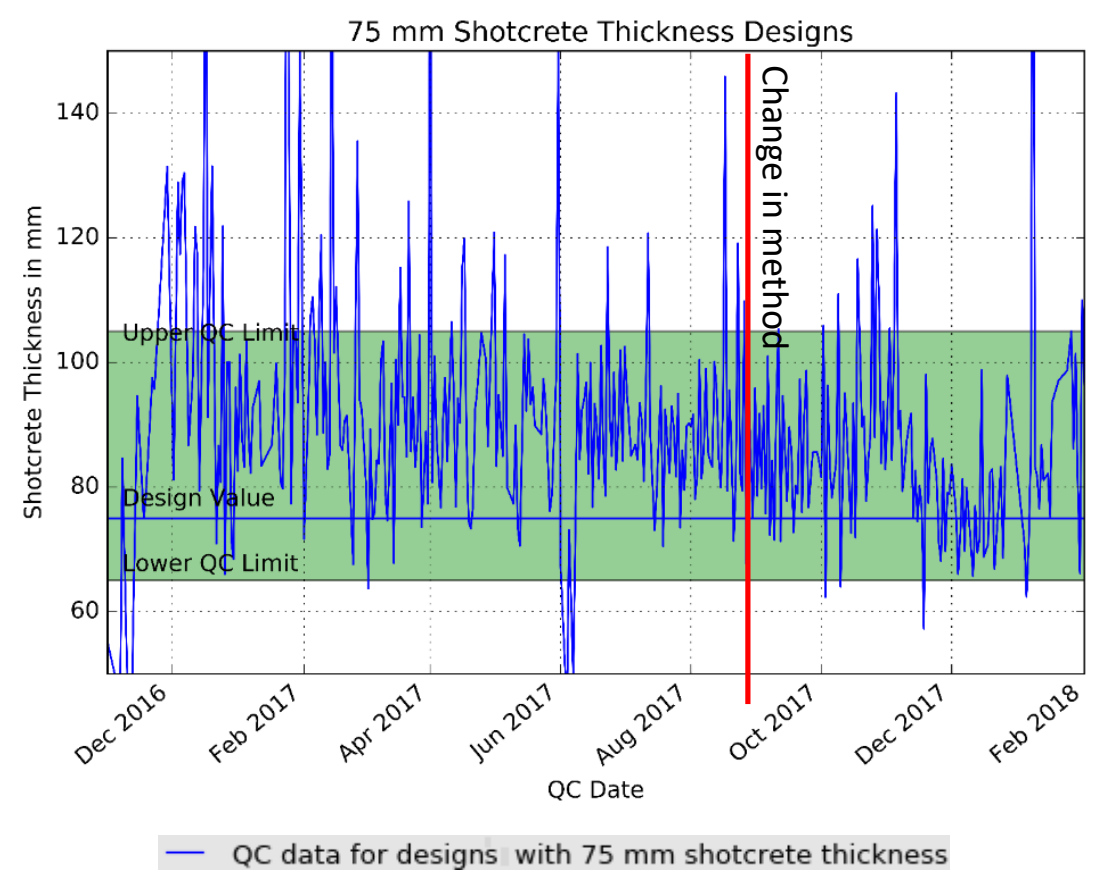

Figure 10 Shotcrete thickness against time. Note the lack of any major steps in the data unlike bolt spacing, and the long-term trend towards both design thickness and reduction in large overspray events over time. Red line indicates the change between methods for collecting thickness measurements

\subsection{Contractor management}

Efficient and systematic management of data at OT provides accurate tracking of KPIs in a transparent manner. The owners team and contractors alike have access to the raw data and can also view all end of month reports through the online data visualisation and reporting platform. This data is made available every shift as it is collected. All personnel can see the performance of the contractor historically and month to date. This means all parties can easily review the compliance to excavation design and the ground support installation performance, reducing knowledge silos and divisive mentalities. It promotes the attitude that there is one 'best for project' solution, creating and fostering a team approach.

Increased visibility and communication of the collected data has led to ownership of the results by contractors and a general desire to improve and work together to produce a better overall product by all teams. When operators can see in detail the success of the round that they have worked on the previous day, it helps drive continual improvement through understanding.

With the remote location of Mongolia, the structured nature of the data management storage and the reporting ability through a widely accessible platform means that stakeholders around the world can have access to the data in real time. It is possible for design teams and management in Brisbane to understand how development is proceeding and what feedback and improvements are being undertaken to the development cycle, as well as the outcomes of this feedback.

\section{Conclusion}

Structured data management at OT has led to measured improvements to efficiency and safety of the underground mine development cycle. A valuable database has been developed from sources including detail captured through quality assurance measurements from suppliers, data collection and mapping onto tablets from laser scanning of every heading, and other methods. It has allowed the delivery of that data in an easily accessible and validated manner. The application of the system has expedited faster analysis of the data and rapid reporting, providing feedback into the development cycle and back to the operators. This has led to development cycle improvements such as reduced shotcrete overspray and increased 
compliance to excavation design (both overbreak and underbreak). Contractor management is greatly aided by reducing knowledge silos, and having open access to data across all teams and a shared understanding of how compliant development is to excavation and ground support designs. Additional analyses can also be undertaken, providing further insight into external factors affecting development compliance, which may have previously not been identified.

\section{Acknowledgement}

The authors acknowledge Mr Gert van Hout, Mr Christopher Carlson, Dr Jean-Philippe Mercier and Mr Sean Kelly for their assistance with internal review and comments, the wider OT Geoscience Team for the work on data collection and processing, and the Rio Tinto Copper \& Diamond Technical Group for the development of CaveCad.

\section{References}

Oyu Tolgoi LLC 2016, Oyu Tolgoi Underground Feasibility Study, Oyu Tolgoi LLC, Ulaanbaatar.

Savage, E, Talu, S, Sturm, P \& Van As, A 2016, 'Development and implementation of the CaveCad ground support module for cost and safety improvements in block cave mines', Proceedings of MassMin 2016, The Australasian Institute of Mining and Metallurgy, Melbourne, pp. 769-772.

Zoller + Froehlich GmbH 2018, Z+F Imager 5010C Datasheet, Zoller + Froehlich GMBH Wangen im Allgäu, viewed 8 August, 2018, http://www.zf-laser.com/fileadmin/editor/Datenblaetter/Z_F_IMAGER_5010C_Datasheet_E.pdf 